\title{
Correction to: Sleep improvement after hip arthroplasty: a study on short-stem prosthesis
}

\author{
Josef Hochreiter $^{1} \cdot$ Harald Kindermann ${ }^{2} \cdot$ Georg Mattiassich $^{3} \cdot$ Reinhold Ortmaier $^{1,4} \cdot$ Marian Mitterer $^{5}$ (D)
}

Published online: 20 August 2019

(C) SICOT aisbl 2019

\section{Correction to: International Orthopaedics} https://doi.org/10.1007/s00264-019-04375-1

There is an error in the Original Publication of this paper.

Authors first and last names have been interchanged. The correct presentation is given above.

The original article has been corrected.

Publisher's note Springer Nature remains neutral with regard to jurisdictional claims in published maps and institutional affiliations.

The online version of the original article can be found at https://oi.org/ 10.1007/s00264-019-04375-1

Marian Mitterer

marian.mitterer@me.com

Josef Hochreiter

josef.hochreiter@ordensklinikum.at

Harald Kindermann

harald.kindermann@fh-steyr.at

Georg Mattiassich

georg.mattiassich@gmx.at

Reinhold Ortmaier

r.ortmaier@gmail.com
Department of Orthopedic Surgery, Ordensklinikum Barmherzige Schwestern Linz, Vinzenzgruppe Center of Orthopedic Excellence, Teaching Hospital of the Paracelsus Medical University, Salzburg, Austria

2 Department of Marketing and Electronic Business, University of Applied Sciences Upper Austria, Campus Steyr, Wels, Austria

3 Trauma Center Graz, Graz, Austria

4 Institute for Sports Medicine, Alpine Medicine and Health Tourism (ISAG), Tirol Kliniken GmbH, Innsbruck and UMIT, Hall in Tirol, Austria

5 Department of Orthopaedics and Traumatology, Paracelsus Medical University Salzburg, Müllner Hauptstrasse 48, 5020 Salzburg, Austria 